\title{
Dinâmicas imobiliárias e políticas urbanas no centro de São Paulo: uma discussão sobre gentrificação na Mooca
}

\author{
Real estate dynamics and urban policies \\ in the central region of São Paulo: a discussion \\ about gentrification in the district of Mooca
}

Michelly Lima Reina Francisco de Assis Comarú

\begin{abstract}
Resumo
0 artigo visa realizar uma análise das dinâmicas imobiliárias e políticas urbanas na região central de São Paulo, particularmente no distrito da Mooca, na perspectiva de discutir em que medida está ocorrendo ou caminha-se para um processo de gentrificação. Realizou-se uma revisão bibliográfica com vistas a embasar a conceituação de gentrificação segundo análises realizadas em países do Norte. São apresentados e analisados dados de fontes secundárias, na forma de tabelas, mapas temáticos e gráficos que permitem uma leitura espacial importante. Visitas de campo e entrevistas com atores locais permitiram identificar uma tendência à elitização dos serviços e comércios. Nota-se que está em curso, uma dinâmica, ainda inconclusa, que, segundo informa a literatura, tem uma série de ingredientes do processo de gentrificação.
\end{abstract}

Palavras-chave: política urbana; gentrificação; valorização; centro de São Paulo.

\begin{abstract}
This article aims to analyze the real estate dynamics and urban policies in the central region of São Paulo, particularly in the district of Mooca, and to discuss to what extent a gentrification process will occur or is already under way. We base the concept of gentrification on a literature review according to analyses carried out in northern countries. Data from secondary sources are presented and analyzed in the form of tables, thematic maps and graphs, which enable an important spatial reading. Field visits and interviews with local stakeholders have identified a tendency towards elitist services and trades. According to the literature, this ongoing, unfinished dynamics has a number of ingredients of the gentrification process.
\end{abstract}

Keywords: urban policy; gentrification; valuation; São Paulo's central region. 


\section{Apresentação}

Uma das hipóteses adotadas aqui é que a reversão no processo de esvaziamento populacional nos distritos centrais de São Paulo, ocorrido na década de 2000, se deu, em parte, devido à atração exercida por novos empreendimentos imobiliários, aparentemente destinados a um novo perfil populacional, provenientes de faixas de maior renda, gerando assim uma alteração na composição residencial com potencial para uma gradativa substituição da população de renda mais baixa.

Busca-se aqui analisar as transformações da produção habitacional do centro de São Paulo, entre 1990 e 2010, bem como suas relações com um novo potencial perfil populacional dos moradores do centro nesse mesmo período.

A revisão da literatura internacional permitiu relatos sobre as alterações na composição populacional de moradores de áreas centrais, em meio às ações do mercado e do Estado capitalista, que acabaram gerando a substituição da população mais pobre por populações provenientes de faixas de renda superiores, processo identificado como gentrification. Decidimos então discutir indícios e tendências da ocorrência desse processo no centro de São Paulo, com enfoque no distrito da Mooca, que, no período analisado (1990-2010), apresentou a maior concentração de lançamentos imobiliários da região central, principalmente de unidades residenciais de 3 e 4 dormitórios.

Neste estudo, considerou-se que o centro de São Paulo é composto pelos distritos: Barra Funda, Bela Vista, Belém, Bom Retiro, Brás, Cambuci, Consolação, Liberdade, Mooca, Pari,
República, Santa Cecília e Sé. Este trabalho visa analisar a produção imobiliária residencial de mercado e transformações nos territórios do centro de São Paulo, especificamente no distrito da Mooca, nas décadas de 1990 a 2010, buscando-se identificar tendências de processos de gentrificação e elitização.

\section{Introdução}

Diversas transformações têm marcado a paisagem urbana e alteram as relações de ocupação e apropriação do território. Na maior metrópole brasileira, não foi diferente. Assistimos ao incremento de um processo de decadência e desvalorização do centro de São Paulo, desde as décadas de 1960, influenciado pelo abandono do centro pelas elites paulistanas em direção às novas centralidades residenciais e comerciais da cidade principalmente no eixo sudoeste (Teixeira et al., 2001).

Nesse contexto, a atual configuração do espaço urbano brasileiro é resultado das transformações do modo capitalista de produção, da atual flexibilização da economia e das relações entre produção e consumo. A apropriação da cidade obedece às lógicas de atuação do mercado capitalista de produção da moradia, refletidas na atual organização do território (Villaça, 2001; Benko, 2002).

Em São Paulo, assim como em outras inúmeras cidades do mundo, as transformações ocorridas na área central, nos últimos anos, revelam uma dinâmica particular de atuação do capital, num ciclo histórico de investimento - desinvestimento reinvestimento (Smith, 2006). 
A dinâmica populacional da cidade caracterizava-se nos anos 1980 e 1990, por uma paulatina diminuição populacional nas áreas centrais e drástico aumento nas regiões periféricas. Essa dinâmica apresentou alterações na última década (2000/2010), proporcionando uma pequena, mas marcante, reversão do processo de esvaziamento do centro e também taxas reduzidas de crescimento da periferia, quando comparadas com as décadas anteriores.

Buscando compreender essas transformações no centro de São Paulo, procuramos, a seguir, realizar uma discussão a partir da literatura internacional sobre as dinâmicas e agentes envolvidos na transformação das áreas centrais, durante o processo de gentrificação. Identificamos duas correntes principais do pensamento, representadas por Neil Smith e Chris Hamnett.

\section{Gentrificação: em busca de conceituação}

Foi a socióloga Ruth Glass que inaugurou, em 1964, o termo "gentrification" para definir a transformação da composição social dos residentes dos antigos bairros operários em Londres, onde ocorreu a substituição de camadas populares por camadas assalariadas de renda média (Smith, 2006).

Chris Hamnett, de tradição humanista liberal, enfatiza interpretações que privilegiam a escolha, a cultura, o consumo e a demanda. 0 autor identifica muitas cidades na América do Norte, Europa e Austrália, sendo, para ele, um fenômeno muito concentrado geograficamente. Define a gentrificação como um fenômeno físico, econômico, social e cultural, verificado na invasão de uma classe média aos bairros ocupados anteriormente pela classe trabalhadora, identificando as chamadas "Áreas Crepúsculo" que passaram por um processo de valorização e aumento do preço dos aluguéis. Para Hamnett, os aspectos principais do processo de gentrificação são a moradia e os residentes (Hamnett, 1991, apud Freitas, 2006)

De forma conclusiva, Hamnett (1991) define que a gentrificação consiste em:

$$
\begin{aligned}
& \text { [...] um processo de transformação da } \\
& \text { composição social dos residentes de um } \\
& \text { bairro, mais precisamente da substituição } \\
& \text { de camadas populares por camadas mé- } \\
& \text { dias assalariadas; e se constitui em um } \\
& \text { processo de natureza múltipla: de inves- } \\
& \text { timento, de reabilitação e de apropriação, } \\
& \text { por essas camadas sociais, de um estoque } \\
& \text { de moradias e de bairros operários ou } \\
& \text { populares. (Hamnett,1991, apud Mourad, } \\
& \text { 2001, p. 7) }
\end{aligned}
$$

Em outra corrente, está Neil Smith, geógrafo escocês, de tradição marxista que, ao estudar o caso de Nova York, identifica o que ele chamou de três ondas no processo de gentrificação. Para Smith, o início de processo, primeira onda, entre os anos de 1950 a 1970, ocorre de forma pontual e esporádica, promovido por artistas que instalaram seus ateliês e passaram a viver em bairros como Greenwich Village e Soho. Posteriormente, a segunda onda, entre o fim dos anos 1970 e início dos anos 1980, a promoção desses bairros é assumida pelos promotores imobiliários e, finalmente torna-se uma estratégia da cidade, atingindo todos os bairros da área central, durante a terceira onda, a partir de 1994, este momento, mais que edifícios reabilitados e apartamentos reformados, 
a gentrificação abrange novos restaurantes, as vias comerciais, os parques, as torres de marcas famosas, os museus das grandes fundações. Assim, a gentrificação passa a interferir e reformular a apropriação do espaço urbano, não só localmente, mas de forma altamente integrada no espaço (Smith, 2006).

No pensamento de Smith, o processo passa, então, a modificar os usos e as funções do espaço gentrificado. 0 comércio passa a se especializar em produtos e lojas mais sofisticadas, condizentes, com o novo perfil populacional esperado para a região valorizada e atrativa economicamente e podemos dizer que existe então uma elitização desta região.

Buscando alguns indícios sobre a metodologia de pesquisa da gentrificação, encontramos alguns argumentos expostos por Neil Smith. Ele insiste que uma teoria da gentrificação tem que explicar o processo histórico de desvalorização do capital no centro da cidade e de que modo essa desvalorização produz a possibilidade de reinvestimento lucrativo. Ele acredita que o nexo crucial está entre o valor da terra e o valor da propriedade. Para isso, o autor está convencido da necessidade de desmembrar essas duas medidas de valor em quatro categorias relacionadas: o valor da moradia, o preço de venda, a renda da terra capitalizada e a renda da terra potencial, ideia formulada na sua teoria do rent gap (Smith, 1996).

Assim, segundo o mesmo autor, o processo de declínio do centro consiste em alguns estágios. 0 primeiro diz respeito à construção e ao primeiro ciclo de uso de um imóvel. Em uma vizinhança nova, o preço da moradia reflete o valor da estrutura e das benfeitorias mais a renda da terra capturada pelo proprietário do terreno. Nessa fase, a renda da terra provavelmente aumentará enquanto o desenvolvimento urbano avança e o valor da moradia começa a declinar muito lentamente. 0 que resulta na elevação do preço do imóvel (Smith, 1996).

Contudo, uma desvalorização sustentada pode eventualmente ser posta em prática de três maneiras (Smith, 1996). Primeiro, através de avanços na produtividade do trabalho. Inovações tecnológicas e mudanças na organização do processo produtivo fazem com que uma estrutura possa ser produzida por um valor mais baixo do que a anterior. Segundo, 0 obsoleto pode transformar-se em estilo, e isso pode também estimular a depreciação sustentada do mercado de moradia promovendo o aumento dos preços das casas antigas, sendo essas mais vendidas que as novas. A terceira forma diz respeito ao desgaste físico. Esse também reflete o valor do imóvel o que implica reparos menores e regulares para manter seu valor. Com o tempo, todavia, surgem problemas maiores de ordem estrutural, como substituição de tubulação e sistema elétrico que são mais onerosos e que tornam a habitação inaceitável sem que sejam realizados. Depois de um ciclo de uso, esses reparos tornam-se necessários, e isso envolve investimentos substanciais (Smith, 1996).

Então, a desvalorização induzirá a redução dos preços comparativamente às novas moradias, mas a extensão mais ampla dessa redução dependerá do quanto a renda da terra também mudou neste meio tempo. Para Smith (1996), o papel do proprietário no processo de desvalorização do imóvel é muito importante. Em geral, após o primeiro ciclo de uso, os proprietários que habitam seus imóveis poderão abrir mão desse direito, sair em busca de 
residências mais novas e alugar o imóvel em processo de depreciação. Se a demanda por essas moradias for alta, o proprietário manterá a moradia empreendendo reformas, reparos, etc. Caso haja de fato um declínio do mercado, a não conservação tenderia a ser a resposta do proprietário.

Essa falta de conservação acontece para liberar dinheiro que será usado em outro lugar. Se a desvalorização avança e não há interesse em reinvestimento na área, o valor dos imóveis cai, e os níveis de renda da terra capitalizada para a área descem abaixo da renda potencial da terra. Os indivíduos que conservassem suas propriedades seriam forçados a cobrar aluguéis mais altos que a média com a esperança de conseguir inquilinos com altos rendimentos. No entanto, para Smith, essa atitude não seria bem-sucedida devido ao tão celebrado efeito de vizinhança, o qual opera através da estrutura de renda da terra (Smith, 1996).

Na sequência do processo de desinvestimento, com a ausência dos empreendedores, a vizinhança em declínio pode vivenciar também um estágio de (re)ocupação o que confere ao espaço alguma popularidade (blockbusting). Após esse período de popularidade, o valor das propriedades tende a declinar. Isto ocorrerá porque as casas foram vendidas por preços inflacionados, e, consequentemente, a ausência de recursos de seus novos ocupantes contribuirá, com o tempo, para a submanutenção dos imóveis (Smith, 1996).

Assim, acreditamos que, a atuação do mercado imobiliário na desvalorização fundiária, aliada à falta de intervenção direta ou indireta do Estado por meio de qualquer investimento público de melhorias urbanas, contribui para o processo de desqualificação da região.
0 último estágio desse processo de desinvestimento é o abandono do imóvel pelo proprietário. Isto ocorre quando o proprietário não pode mais auferir uma renda suficiente para cobrir os custos básicos de serviços e taxas. Os edifícios são abandonados por seus proprietários porque não podem ser mais utilizados lucrativamente (Smith, 1996). No Brasil, nos centros urbanos, esse processo de desinvestimento pode ajudar a explicar, em parte, a grande proporção de imóveis desocupados.

No caso brasileiro, esse último estágio pode estar relacionado às grandes dívidas especialmente, de IPTU, que em alguns casos, pode superar o valor do imóvel e, por isso, o proprietário prefere abandoná-lo a pagar as dívidas. Este é o caso de alguns edifícios vazios durante anos no centro de São Paulo. ${ }^{1}$

Trabalha-se aqui com a hipótese de que mesmo obedecendo a uma descrição do mercado norte-americano, a teoria de Neil Smith pode ser, em alguma medida, útil à compreensão parcial das dinâmicas nos centros urbanos brasileiros.

De forma geral, nota-se que os debates em torno do processo de gentrificação não apresentam uma homogeneidade e dependem do ponto de vista que temos sobre ele. A aproximação se dá somente em sua definição, a substituição de uma população de menor renda, por classes de maior renda. A metodologia utilizada para identificar o processo também é muito diversificada, cabendo sempre uma análise sobre a questão da moradia em regiões centrais ou consolidadas da cidade.

Em seus estudos sobre gentrificação, Smith (2006, p. 74) afirma que em São Paulo até 2006 "o processo é espacialmente isolado e se encontra praticamente no início", indicando 
que São Paulo não havia conhecido nem a primeira nem a segunda fase da gentrificação, ou seja, para ele, primeiramente um processo que ocorre de forma pontual e esporádica, promovido em parte por artistas que instalam seus ateliês e passam a viver em bairros centrais, e posteriormente, a promoção desses bairros é assumida pelos promotores imobiliários.

Com relação ao centro de São Paulo, poderíamos arriscar que alguns bairros já vivenciam a primeira fase da gentrificação, outros já entraram na segunda fase e outros ainda estão prestes a entrar na segunda fase.

Além disso, cabe ressaltar que o poder público tem tido um papel importante e contraditório, ora promovendo políticas de inclusão e proteção social (no mais das vezes em atendimento a demandas e pressões de grupos organizados e movimentos populares urbanos), ora adotando o discurso pró elitização e promovendo políticas de incentivo à atração de investidos privados para inflar o ambiente de negócios na cidade.

\section{0 centro de São Paulo}

0 processo de transferências das elites paulistanas do centro em direção às novas centralidades promoveu, desde a década de 1960, uma tendência de popularização do centro do São Paulo, principalmente em relação ao comércio e escritórios de profissionais liberais destinado ao atendimento da população de mais renda mais alta. A saída encontrada pela economia local foi a popularização do comércio, até em estabelecimentos sabidamente mais sofisticados, como o Mappin, localizado no centro da capital (Villaça, 2001)

Nakano, Rolnik e Campos (2004) nos mostram que o surgimento de novas centralidades em São Paulo, primeiramente em direção à Avenida Paulista, deu-se em meio a uma dicotomia.

A migração da centralidade dominante deriva do modo de urbanização paulistana, exacerbada ao longo da segunda metade do século XX. Processos legais e extralegais de ocupação espacial imprimiram em São Paulo uma ordem territorial marcada pela dicotomia entre as áreas residenciais de alto padrão, concentradas no quadrante sudoeste, e os bairros populares que se espalharam em todas as direções da periferia. (Nakano, Rolnik e Campos, 2004, p. 125)

A história recente da cidade mostra que o processo de abandono e desinteresse de atuação no centro, promovido tanto pelo poder público, quanto pelo mercado imobiliário, constitui-se direta ou indiretamente na formação de uma reserva de território, de localização, mais do que apenas e simplesmente, um processo demográfico de transferência populacional.

A cidade de São Paulo, assim como metrópoles de outros países, como os Estados Unidos, tem seus business districts, e a territorialização desse moderno setor econômico se dá de forma bem clara, em outra centralidade, na região oeste, próximo à Marginal do Rio Pinheiros e da Avenida Luiz Carlos Berrini. Muitos investimentos públicos foram consolidados nessa região como forma de valorização e "embelezamento" da paisagem da região com a construção da Ponte Estaiada (Ferreira, 2004). 
Claramente, todo esse "esforço" público e privado não pôde ser dirigido aos mais pobres, isto porque a população moradora de favelas da região foi removida para outras regiões da cidade agravando assim a segregação socioespacial na metrópole (Fix, 2009). Ressalta-se, assim, um processo de territorialização do capital na cidade de São Paulo, onde os investimentos públicos privilegiam e valorizam ainda mais o patrimônio dos mais ricos, restringindo a ocupação da população de baixa renda às periferias (Fix, 2009; Villaça, 2001).

Paralelamente ao processo de constituição de novas centralidades na cidade de São Paulo, primeiramente em direção à Avenida Paulista e posteriormente em direção ao eixo sudoeste, aliado aos investimentos públicos em grandes obras viárias, como a Ponte Estaiada, o processo de "abandono" do centro de São Paulo pode ser considerado gradativo, cumulativo e mais complexo, conforme Teixeira et al. (2005):

0 abandono das áreas centrais pelas elites, entretanto, nunca foi total. Principalmente pelo fato de o valor simbólico e histórico das áreas centrais não ser reprodutível em outras áreas. No início da década de 1990, com uma construção dos grandes proprietários, ganha força a ideia de que o Centro precisava de uma "revitalização", significando uma iniciativa de retorno de uma sociabilidade de classe média e de elite às áreas centrais. (pp. 4-5)

Diante da diminuição populacional, especialmente da população de renda mais alta, direcionada às novas centralidades, bem como com o processo de transferência das sedes empresariais para o eixo sudoeste, algumas iniciativas foram propostas tanto pelo poder público municipal quanto pela sociedade civil, como veremos a seguir. A atuação do poder público municipal de São Paulo para atrair novos investimentos privados para a área central foi caracterizada por alguns projetos de intervenção urbanística e legislativa.

\section{Breve histórico sobre programas e diretrizes para o centro}

Foi durante a gestão da prefeita Luiza Erundina (1989-1992) do PT que ocorreu a aprovação da primeira Operação Urbana na cidade de São Paulo, a Operação Urbana Anhangabaú. Naquela mesma gestão, na área da habitação, considera-que a política implementada superou a produção tradicional de unidades novas para venda em grandes conjuntos periféricos produzidos por empreiteiras, ampliando-se o leque de políticas por meio da: construção de unidades novas (em conjuntos pequenos) através de mutirões em cogestão em parceria com associações de moradores e movimentos de moradia (Felipe, 1995; Comaru, 1998). Não se chegou, obviamente, a fazer frente à enorme demanda quantitativa existente, mas a iniciativa representou um momento relevante em termos de inovação no sistema de produção, em termos de custos, qualidade da arquitetura e localização dos conjuntos (Bonduki et al., 1993).

Na gestão do prefeito Paulo Maluf (1993-1996) do PP, em relação a habitação desarticularam-se o papel das estruturas administrativas $^{2}$ e os procedimentos relacionados 
com as políticas urbanas e sociais do governo anterior; paralisaram-se os empreendimentos por mutirão; deu-se continuidade às obras por empreiteira, fortalecendo a terceirização dos serviços técnicos (Ikuta, 2008; Felipe, 1995).

Em relação ao centro, o Programa de Requalificação Urbana e Funcional da Área Central - Procentro foi iniciado nesta gestão, mas 0 financiamento do Banco Interamericano de Desenvolvimento só chegou em 2004. ${ }^{3}$ A gestão do prefeito Celso Pitta também do PP (19972000) não apresentou nenhuma política expressiva para o centro da cidade.

Na gestão da prefeita Suplicy (20012004) do PT, o Programa Morar no Centro, ${ }^{4}$ buscava, entre outras ações, realizar a "recuperação e requalificação de edifícios que se encontram vazios, subutilizados e degradados, para uso residencial, destinados a famílias com renda entre 0 e 6 salários mínimos", através de ações de "melhoria ambiental no Perímetro de Reabilitação Integrada do Habitat (PRIH-Luz)", na estruturação de um Programa de Locação Social, "mediante a construção de pequenos edifícios em lotes intersticiais para uso residencial, tendo como público-alvo famílias e pessoas sós com renda inferior a três salários mínimos", além da melhoria das condições de vida em cortiços e moradias coletivas e urbanização e regularização fundiárias de favelas, como no caso da favela do Gato.

Já na gestão dos prefeitos José Serra (2005-2006) e Gilberto Kassab (2006-2008) a iniciativa mais expressiva foi referente ao programa "Nova Luz", com um destaque também para a Lei de Incentivos Seletivos. O Programa visou incentivar a implantação de novas atividades comerciais e de prestação de serviços, mais sofisticados que as existentes como: galerias de arte, shopping centers, escritório de marketing e propaganda, entre outras, com 0 objetivo "de promover e fomentar o desenvolvimento adequado da região". 5

Silva (2006), em uma análise geral do programa de incentivos seletivos, comenta que:

As atividades incentivadas são muito específicas e diferentes das que existem atualmente no perímetro. Isso beneficiaria os serviços especializados que empregam poucas pessoas e o comércio concentrado (lojas de departamentos, shoppings) em detrimento das atividades atuais (pequeno e médio comércio, pequenos escritórios, etc.) que geram muitos mais empregos. A escolha das atividades parece encaminhar para um processo de substituição das atividades e consumidores populares, por outros mais sofisticados (gentrificação). (p. 100)

Notamos assim que o Programa de Incentivos Seletivos, parecia ser uma tentativa do poder público em valorizar a região transformando a paisagem do centro, com a oferta de novas atividades de comércio e serviços, voltadas aos consumidores de renda média, em contradição às atividades que lá se encontram, bem como ao perfil popular dos consumidores. Esse tipo de programa, se bem-sucedido, tende a induzir um processo de elitização do centro.

Além das transformações urbanísticas, 0 projeto previa uma transformação do perfil populacional da região. A estratégia de transformação do perfil populacional foi baseada numa dinâmica de substituição e atração, em que o morador atual seria substituído por pioneiros, e esses por sua vez trariam novos seguidores e juntos mudariam totalmente o perfil da região, como descrito detalhadamente no site do programa. Fica clara a ideia de substituição 
da atual população moradora, bem como do atual comércio, por uma população de renda mais alta e de serviços mais sofisticados para atender a um novo perfil. Tratou-se, assim, de uma iniciativa pública com fins explicitamente renovadores e gentrificadores.

Em junho de 2012, o Projeto Nova Luz foi paralisado por ação judicial ${ }^{6}$ da Defensoria Pública e deferida pela juíza Alexandra Fuchs de Araújo que evidenciou a falta de participação popular na aprovação do projeto e inexistência de um cadastro de moradores que seriam atingidos no perímetro de intervenção, mostrando descomprometimento do poder público com a população da região. Ademais o prefeito Haddad do PT, ao assumir o mandato em 2013 acenou para a revisão de diretrizes e formas de implantação do projeto.

Nota-se que a organização e a mobilização dos moradores, comerciantes e trabalhadores da região da Santa Efigênia, foram decisivas para influenciar na decisão da juíza. Quando se analisa o projeto, percebe-se uma intenção clara de promover alteração do perfil populacional e dos frequentadores da região, atraídos pela presença de renovados equipamentos culturais e por um novo e sofisticado comércio estimulador de um processo de gentrificação.

Paralelamente, a atração do mercado imobiliário passa a ser a combinação do passado com o futuro, dos benefícios já existentes, como a oferta de transporte público, postos de trabalho e comércio, com os novos serviços da vida moderna, com muita cultura e entretenimento: "Vivendo de maneira inteligente no centro".?

\section{Mercado imobiliário}

\section{no centro}

Nas últimas décadas, como mencionado, o centro vem passando por um processo de desvalorização imobiliária, incrementado pela popularização do comércio e diminuição populacional. Nesse contexto, as iniciativas do poder público, constituíram-se através de políticas especificas para a região central, ora para atrair novos investimentos privados no setor imobiliário residencial, de comércio e serviços, em padrões diferentes dos já estabelecidos no centro, por meio de instrumentos urbanísticos, como as Operações Urbanas; ora promovendo o incremento da habitação social como forma de reverter o processo de esvaziamento populacional e de garantir moradia digna nas regiões consolidadas da cidade.

Nesse contexto, a atuação do mercado imobiliário, como uma das molas propulsoras do retorno populacional e de ocupação de regiões dotadas de infraestrutura urbana e serviços, pela presença de novos lançamentos imobiliários, configurando-se como uma hipótese importante a ser checada.

Em suas pesquisas sobre a dinâmica imobiliária do setor comercial na cidade de São Paulo, Sandroni (2004) reitera a conhecida tese do surgimento de novas centralidades, a partir da década de 1960, inicialmente em direção à Av. Paulista, e posteriormente em direção às avenidas Berrini e Faria Lima. A acentuada queda de preços do $\mathrm{m}^{2}$ comercial, observada na cidade entre 1999 e 2003, contribuiu para 
o esvaziamento da região central. As empresas que pretendiam se transferir para regiões de melhor griffe não o faziam devido aos preços elevados. Tiveram, nessa conjuntura de baixa, 0 momento oportuno para efetuar o deslocamento (Sandroni, 2004, p. 368).

Para esta análise, utilizamos informações do banco de lançamentos imobiliários residenciais da Empresa Brasileira de Estudos do Patrimônio (Embraesp). Esses dados são referentes aos distritos do centro de São Paulo entre 1990 e 2010. 0 banco de dados é composto por empreendimentos verticais e horizontais, que foram objeto de comercialização e propagandas nos meios de comunicação (jornais, revistas, panfletos, e aprovados pela Secretaria da Habitação do Município de São Paulo).

Na década de $1990,{ }^{8}$ cerca de 191.361 unidades residenciais foram lançadas no município de São Paulo; dessas, 18.447 no centro da cidade, uma participação de $9,6 \%$ de toda produção. Percebe-se o aumento da produção imobiliária de novas unidades no centro de São
Paulo, a partir de 1994, bem como um aumento de sua participação na produção de toda a cidade, chegando a 11,3\% e um pico em 1998 com $22,8 \%$ das unidades habitacionais lançadas no município de São Paulo, e um recuo considerável como apresentado na Tabela 1.

0 Gráfico 1 representa o percentual de participação de cada um dos distritos centrais na produção imobiliária da década de 1990.

0 gráfico nos chama atenção para os distritos que foram alvo de nenhuma ou pouca atuação do mercado imobiliário, como Barra Funda, Belém, Bom Retiro, Brás, Pari, República e Sé, evidenciando o pouco interesse e/ou incidências de restrições ao mercado para atuar nesses distritos. Já na década de 2000, cerca de 300.488 unidades foram lançadas em todo o município de São Paulo. No mesmo período, nos 13 distritos pesquisados, temos um montante de 39.146 unidades lançadas, representando uma média de $13 \%$ da produção do mercado imobiliário na região em relação ao município de São Paulo.

Tabela 1 - Unidades imobiliárias lançadas em São Paulo e nos distritos centrais (1992-1999)

\begin{tabular}{l|r|r|r|r|r|r|r|r|r}
\hline & \multicolumn{1}{|c|}{1992} & \multicolumn{1}{|c|}{1993} & \multicolumn{1}{c}{1994} & \multicolumn{1}{c}{1995} & \multicolumn{1}{c}{1996} & \multicolumn{1}{c}{1997} & \multicolumn{1}{c}{1998} & \multicolumn{1}{c}{1999} & \multicolumn{1}{c}{ Total } \\
\hline MSP & 10.104 & 19.593 & 23.085 & 25.362 & 29.188 & 37.887 & 20.249 & 25.893 & 191.361 \\
Centro & 879 & 835 & 2.611 & 960 & 2.115 & 3.076 & 4.621 & 3.350 & 18.447 \\
$\%$ & 8,6 & 4,2 & 11,3 & 3,7 & 7,2 & 8,1 & 22,8 & 12,9 & 9,6 \\
\hline
\end{tabular}

Fonte: Embraesp. Elaborado a partir dos dados da SMDU/Dipro. 


\section{Gráfico 1- Empreendimentos lançados nos distritos centrais} (1990-1999)

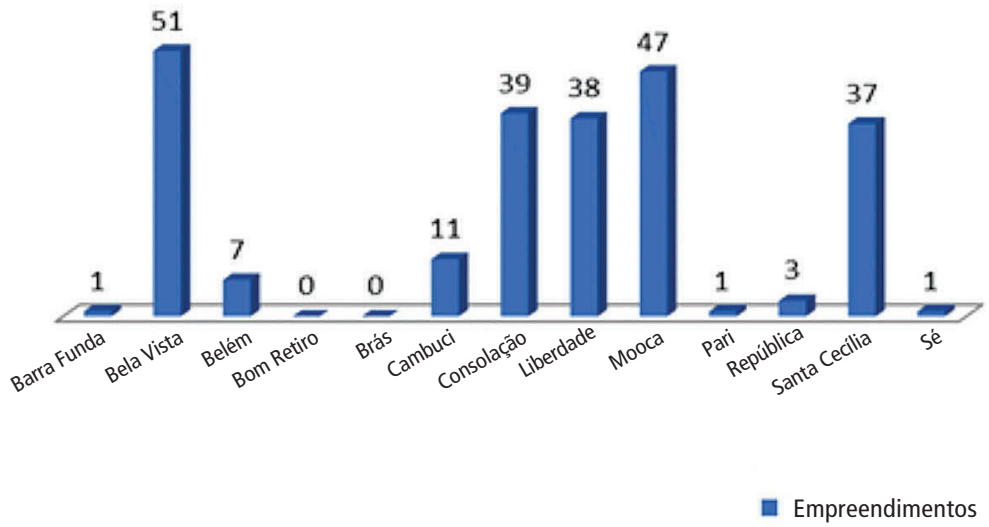

Fonte: Elaboração dos autores a partir dos dados da Embraesp.

Tabela 2 - Unidades imobiliárias lançadas em São Paulo e nos distritos centrais (2000- 2010)

\begin{tabular}{l|r|r|r|r|r|r|r|r|r|r|r|r}
\hline & 2000 & 2001 & 2002 & 2003 & 2004 & 2005 & 2006 & 2007 & 2008 & 2009 & 2010 & Total \\
\hline MSP & 28.676 & 21.714 & 20.243 & 24.442 & 19.720 & 23.541 & 24.736 & 37.107 & 32.577 & 30.558 & 37.174 & 300.488 \\
Centro & 2.289 & 2.125 & 1.354 & 3.280 & 3.484 & 3.104 & 3.071 & 6.100 & 3.181 & 1.918 & 9.192 & 39.146 \\
$\%$ & 7,9 & 9,7 & 6,6 & 13,4 & 17,6 & 13,1 & 12,4 & 16,4 & 9,7 & 6,2 & 24,7 & 13,0 \\
\hline
\end{tabular}

Fonte: Elaboração dos autores a partir dos dados da Embraesp.

A Tabela 2 mostra a relação entre as unidades lançadas no município de São Paulo e no centro, com os números absolutos e sua participação em porcentagem, comparativamente, entre e o centro e município de São Paulo, entre os anos de 2000 e 2010.

Os dados evidenciam um aumento da atuação do mercado imobiliário na região, a partir de 2003 até 2007, somando um total de 19.039 unidades. Contudo, somente no ano de
2010, foram lançadas 9192 unidades, representando cerca de $24,7 \%$ de todas as unidades lançadas em São Paulo, naquele ano.

Em números absolutos, os distritos que mais apresentaram lançamentos foram respectivamente: Mooca, Barra Funda, Bela Vista, Liberdade e Santa Cecília, evidenciando a atuação do mercado, no que denominamos de "anel/fronteira do mercado imobiliário", como veremos adiante. 
Somente 0 distrito da Mooca apresentou um total de 10.226 novas unidades habitacionais, em apenas 10 anos. Somando os cinco distritos que tiveram maior número de lançamentos, chegamos a um total de 28.547 unidades no período. Já o distrito da Sé não apresentou nenhum lançamento imobiliário no período, e os distritos do Pari e Brás, com 268 e 422 unidades, respectivamente, mostrando a pequena participação do capital imobiliário nessa porção do centro. 0 Gráfico 2 mostra a porcentagem das unidades lançadas nos 13 distritos pesquisados, na década de 2000.

Outro aspecto importante na caracterização da incorporação diz respeito à análise dos padrões de distribuição dos lançamentos no espaço. Essa etapa do trabalho baseou-se no uso de ferramentas de Sistema de Informações Geográficas (SIGs) buscando mapear as informações dos lançamentos imobiliários, utilizando o código de endereçamento postal - CEP e o endereço completo, por meio de uma técnica chamada de adressmatching. ${ }^{9}$

Identificamos nos distritos centrais, a produção do mercado capitalista, em dois períodos específicos, entre os anos de 1990 e 1999 e posteriormente 2000 e 2010. Os Mapas 1 e 2 espacializam essa produção nos dois períodos. Na década de 1990, notamos que os distritos do Bom Retiro e Brás não foram alvo de nenhuma produção imobiliária nova. Já os distritos de Santa Cecília, Consolação, Bela Vista, Liberdade e Mooca apresentam grande concentração dessa produção.

O Mapa 2 mostra a produção imobiliária na década de 2000. Percebemos que, neste período, somente o distrito da Sé não foi alvo dessa produção. Como mostramos anteriormente nas tabelas, o distrito que apresenta maior atuação do mercado é a Mooca, com mais de 10 mil unidades construídas no período, concentradas, sobretudo, próximo ao eixo da Rua da Mooca.

\section{Gráfico 2 - Empreendimentos imobiliários lançados nos distritos centrais} (2000-2010)

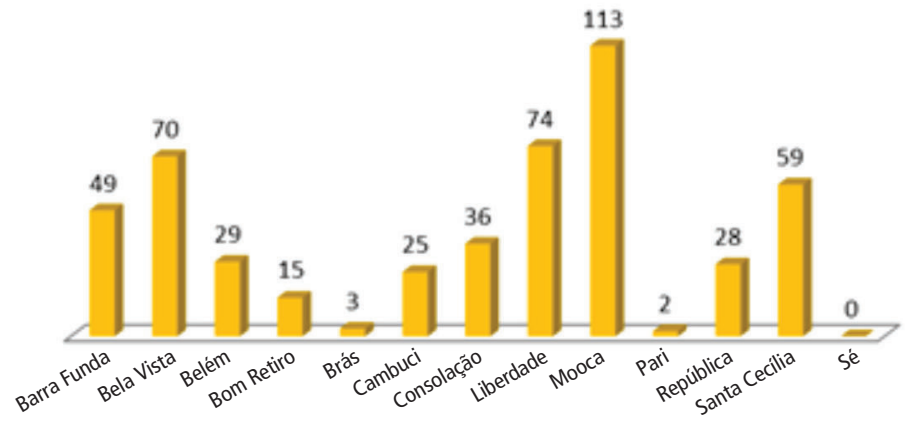


Mapa 1 - Número de dormitórios das unidades lançadas em São Paulo 1990 a 2000

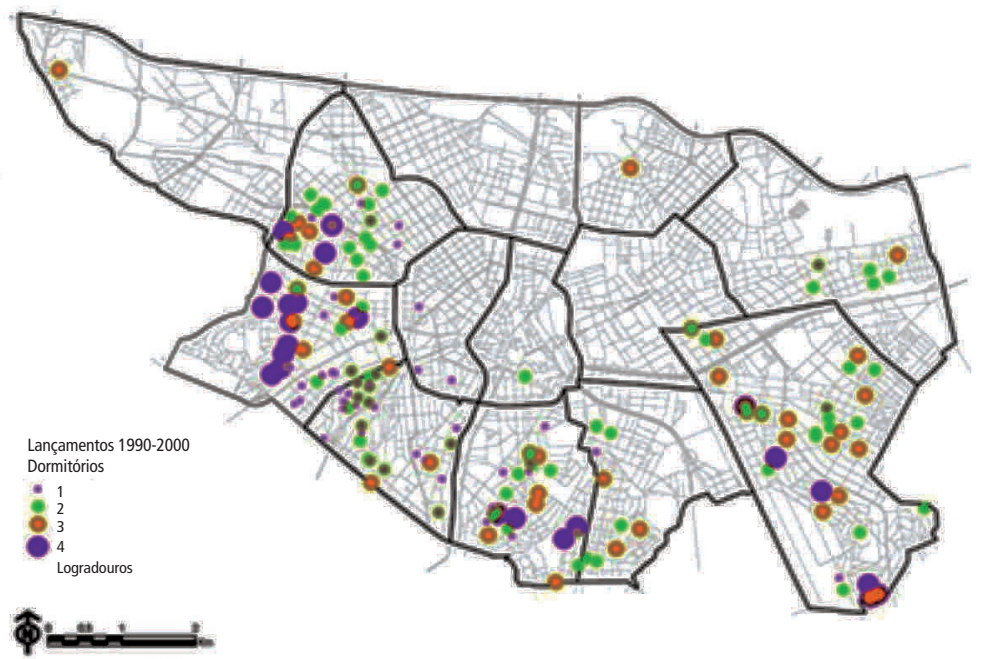

Fonte: Embraesp. Organização: Comaru, Reina (2015).

Mapa 2 - Número de dormitórios das unidades lançadas em São Paulo 2000 a 2010

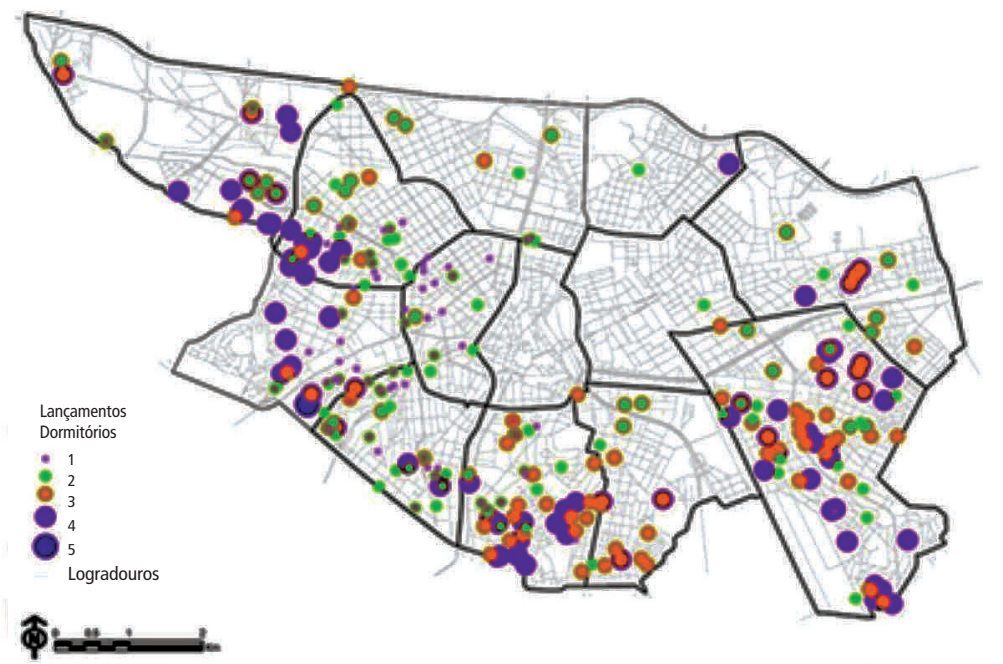

Fonte: Embraesp. Organização: Comaru, Reina (2015). 
Mapa 3 - Lançamentos imobiliários nos distritos centrais 1990-1999

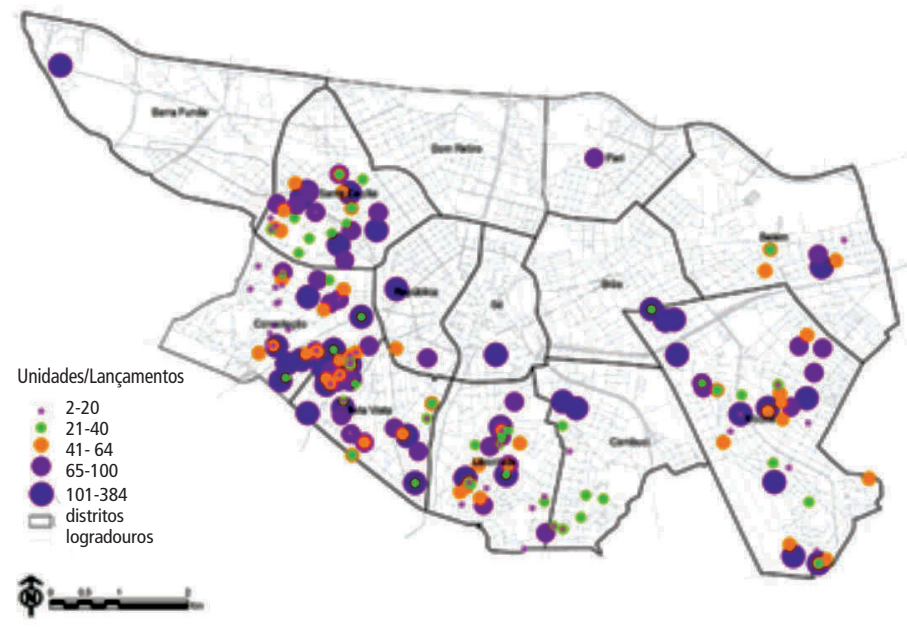

Fonte: Embraesp. Organização: Comaru, Reina (2015).

Mapa 4 - Lançamentos imobiliários nos distritos centrais 2000-2010

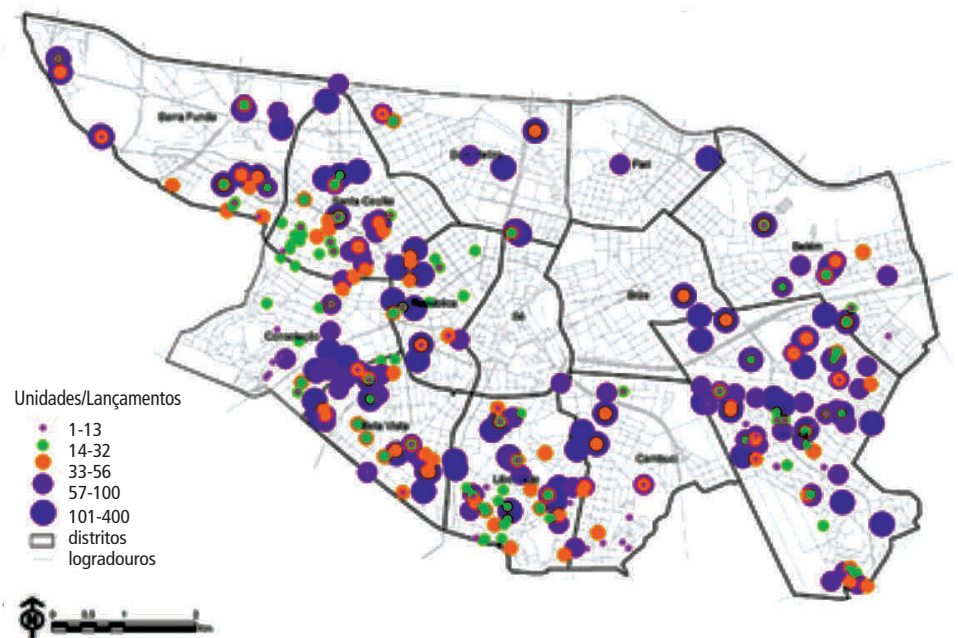

Fonte: Embraesp. Organização: Comaru, Reina (2015). 
Comparativamente, o distrito da Barra Funda, que apresentou somente um empreendimento lançado no período anterior, aparece na década de 2000 com 49 lançamentos, evidenciando a atração que essa região vem apresentando nos últimos anos. 0 anel central de produção imobiliária, como dito, intensifica-se nesse período, em um novo arco, oeste-sul-leste.

Um dos parâmetros importantes relativos ao padrão da produção imobiliária diz respeito ao número de dormitórios de cada unidade. De forma geral, o número de dormitórios está proporcionalmente ligado à área útil das unidades, caracterizando assim, em certa medida, a faixa de renda ou classe social para qual a produção está voltada predominantemente. Nota-se que, na década de 1990, a grande maioria das unidades lançadas são de 2 e 3 dormitórios. As unidades com 4 dormitórios estão localizadas somente nos distritos de Santa Cecília, Consolação, Liberdade e Mooca, uma produção voltada para população de renda mais alta.

Entre todos os empreendimentos lançados entre 2000 e 2010 no centro de São Paulo, $21 \%$ deles tinham unidades com 4 ou mais dormitórios, o que é notável. Em porcentagem da produção, destacam-se os distritos da Barra Funda e da Mooca, com 34\% e 33\%, respectivamente dos empreendimentos com esse tipo de unidade. Fica clara a atuação do mercado imobiliário no sentido de induzir famílias de renda mais alta para essas regiões. Destacamos o caso da Barra Funda, que no período anterior não tinha apresentado nenhuma produção desse tipo e na última década apresentou 17 empreendimentos.
Distritos que já apresentavam uma tendência de maior concentração desse padrão das unidades, como vimos no período anterior, continuaram com essa tendência na última década, especialmente Consolação, Liberdade e Mooca.

Os dados da Embraesp mostram que 0 capital imobiliário ora dedicou seus investimentos em regiões já consolidadas e de presença constante do mercado, ora dedicou-se a promover lançamentos em regiões também consolidadas, mas com pouca produção imobiliária recente (1990-2000).

Na perspectiva de buscar compreender a realidade imobiliária da cidade, Marques (2005) explica que:

[...] a produção do espaço não está associada única nem mesmo principalmente com a expansão urbana de forma "naturalizada", pelo crescimento demográfico. Ao contrário, essa informação confirma que as atividades de produção da cidade estão ligadas à existência de circuitos de valorização fundiária que permitem que um mesmo lugar seja objeto de vários ciclos de valorização, nos quais a riqueza é capturada por meio da transformação e diferenciação dos espaços... (p. 235)

Já os distritos de Santa Cecília, Consolação e Bela Vista que historicamente já concentravam uma população de maior renda quando comparados com outros distritos, como Brás ou Belém, por exemplo, sofreram com uma atuação constante do mercado imobiliário em todo o período pesquisado, evidenciando a presença permanente do capital nessas áreas tidas como "valorizadas" na região.

Os distritos mais próximos do centro antigo, Sé, Pari e Brás, despertaram pouco 
interesse do mercado imobiliário nas últimas décadas. Na década de 1990, a Sé e o Pari registraram o lançamento de somente um empreendimento, cada um, e o Brás não apresentou nenhum lançamento. Na década de 2000, a Sé continuou sem lançamentos imobiliários, o Pari registrou dois empreendimentos lançados, e 0 Brás três empreendimentos.

As causas prováveis desse desinteresse do mercado, podem estar a associadas a ideia de desvalorização e de abandono do centro histórico, muito difundida pela mídia nos últimos anos na capital; as características da estrutura fundiária da região e as limitações impostas pela legislação urbanística.

Ainda sobre essa atuação do mercado, Marques (2005) aponta que:

Aparentemente, os processos de produção imobiliária não têm uma lógica contínua do centro histórico para os espaços exteriores, mas "criam" novas fronteiras de expansão, deixando atrás de si vastas regiões que passam a ser objeto de produção apenas posteriormente, em uma aplicação em escala macro da dinâmica de produção de loteamentos descrita pela literatura há muitos anos. (p. 237)

Nos dois períodos analisados, o distrito que apresentou o maior número de lançamentos imobiliários no centro de São de Paulo foi a Mooca. Enquanto na década de 199041 empreendimentos foram lançados, com 3.563 unidades no total, na década de 2000, foram 113 empreendimentos com 10.226 unidades lançadas, somando-se 13.792 novas unidades habitacionais.

A atuação do mercado em regiões consolidadas pode garantir o que chamamos de "reserva de território", nos vazios urbanos, em regiões onde proprietários e agentes do mercado imobiliário operam aguardando a valorização imobiliária. Na metrópole paulistana, 0 abandono de funções industriais exercidas no início do século vem promovendo mudanças no uso e ocupação do território, quase sempre associadas a uma nova valorização imobiliária, em empreendimentos destinados às famílias com rendas médias e alta.

Pesquisas recentes baseadas em levantamentos de campo na orla ferroviária e visitas promovidas no âmbito desta investigação permitem confirmar que a intensa atuação recente do capital imobiliário na Mooca está associada à transformação de antigas áreas industriais em novas formas de ocupação residencial, associada às classes sociais de renda média e alta (Vitale, 2013).

\section{Estudo de caso: distrito da Mooca}

0 distrito da Mooca em São Paulo fica localizado na região central no eixo centro-leste da cidade, caracterizado principalmente pela forte presença das indústrias, provenientes desde o início da industrialização no país, no início do século $X X$, que ainda marcam a paisagem da região.

Na paisagem atual da Mooca, notam-se muitas edificações fabris, originárias do início do século XX, concentradas, sobretudo, na orla ferroviária, que após o início da desconcentração e desativação de grande parte do parque industrial, a partir da década de 1950, ainda permanecem ocupando grandes lotes industriais na região. 
As mudanças econômicas globais, materializadas na reestruturação produtiva, nas últimas décadas do século passado, acabaram por desconcentrar o parque industrial entre outras regiões da cidade e do país. Assim, as transformações da paisagem urbana da Mooca nos últimos anos refletem uma nova dinâmica econômica da região. Antigos pátios industriais foram desativados, outros, destruídos e, em seus lugares, produzidos condomínios residenciais de médio e alto padrão - associados ao processo mais abrangente de desindustrialização.

Segundo as informações do Censo 2010 do IBGE, a população moradora da Mooca é de 75.724 habitantes. 0 distrito apresenta uma densidade demográfica de $9.834 \mathrm{hab} / \mathrm{km}^{2}$, diante da média do município de São Paulo de 7.458 hab/ $/ \mathrm{km}^{2}$. Na Mooca, o chefe de família apresenta renda mensal de $\mathrm{R} \$ 3.293,49$, comparativamente, no mesmo período, à renda média mensal no município de São Paulo foi de $R \$ 2.160,25$.

Segundo a Embraesp, a área construída referente a imóveis residenciais verticais aumentou cerca de 133\% entre os anos de 1991 e 2010, na Mooca, enquanto a área construída referente a imóveis residenciais horizontais diminuiu $0,5 \%$ no mesmo período, configurando, assim, a expansão crescente do processo de verticalização no bairro.

Paralelamente ao aumento dos lançamentos imobiliários na região, observa-se uma diminuição das áreas destinadas ao uso industrial, já que, no mesmo período, a área construída diminuiu cerca de $27 \%$, confirmando essas transformações recentes no uso e ocupação do território.

0 Plano Diretor aprovado em 2002 e a Lei de Uso e Ocupação do Solo aprovada em 2004 certamente contribuíram para esse incremento de investimentos residenciais de alto padrão na Mooca.

Segundo a mesma pesquisa, de 1991 a 2010 a área construída horizontal para o setor terciário, especialmente comércio e serviços, cresceu 19\%; já a área vertical para o mesmo segmento cresceu mais de 50\%. Evidencia-se, assim, que as transformações do uso e da paisagem da Mooca ${ }^{10}$ implicam mudanças no uso e ocupação do solo, diminuição expressiva da atividade industrial, aumento da área destinada às atividades comerciais e de serviços, especialmente com ocupações verticais, bem como aumento majoritário da moradia verticalizada, configurando-se atualmente como uma região predominantemente residencial.

Sobre as transformações na paisagem da Mooca, graças à atuação do mercado capitalista de produção habitacional, Sales e Baffi (2010) refletem:

[..] um processo de valorização imobiliária, progressivamente desencadeado a partir dos anos 1980, evidencia a tendência de verticalização residencial na área. Verifica-se nos estudos elaborados, que esta destina-se sobretudo ao uso residencial, consolidando-se ao longo da Avenida Paes de Barros, mas encontra-se também disseminada de forma difusa por outras áreas das cotas mais baixas da região. (p. 46) 


\section{Considerações finais}

Consideramos que as ações, programas e projetos de intervenção que previram investimentos privados na região central ainda não geraram alterações profundas na paisagem urbana, mas foram fundamentais na promoção e divulgação de um "discurso potencializador de especulação" sobre as possíveis transformações no uso e ocupação dessa porção do território. Propostas de sofisticação e especialização tecnológica na região da Luz por meio do programa Nova Luz e por meio de incentivos fiscais, proporcionados às empresas que se transferissem para a região, são exemplos deste tipo de intervenção pública e intenção política e econômica.

No centro de São Paulo, identificamos nos últimos anos um retorno do capital imobiliário, especialmente nos distritos localizados nas bordas da região central. Parece que a tendência para os próximos anos é uma atuação do mercado nos distritos mais centrais, como República e Sé que apresentam maior estoque de outorga onerosa, visto que distritos como Mooca, Cambuci, Liberdade, Bela Vista, já não possuem estoque de outorga onerosa. Entretanto, a existência das Operações Urbanas Consorciadas em operação e em fase inicial, tais como: Operação Urbana Centro, Operação Urbana Mooca - Vila Carioca e Operação Urbana Água Branca, por exemplo, ao permitirem a flexibilização dos parâmetros de uso e ocupação do solo podem alterar drasticamente este quadro.

Sobre a atuação do mercado capitalista da moradia, identificamos a localização da produção como um arco da produção imobiliária, em uma fronteira eixo oeste-sul-leste, dentro dos limites aqui estabelecidos do centro de São Paulo. No caso específico do distrito da Mooca, notamos uma tendência crescente do processo de verticalização residencial, aliado ao processo de reutilização de antigas áreas industriais.

Desta produção imobiliária, cerca de $40 \%$ constituem-se de produtos de 3 dormitórios e $32 \%$ compõe-se de unidades com 4 dormitórios ou mais, ou seja, mais de $70 \%$ da produção de imóveis é destinada para extratos de renda média e renda média alta, e em alguns setores, como o alto da Mooca, renda alta.

As referências teóricas conceituais referentes à gentrificação nos informam que o fenômeno está muito mais configurado como processo histórico de médio prazo do que um fenômeno de curta duração.

Por outro lado, apesar de contarmos com alguns autores que teorizaram sobre 0 assunto, ainda há poucos estudos e pesquisas em profundidade no Brasil que auxiliem a produção de uma teoria gestada e validada para a realidade dos países do Sul. Nesse sentido, tomamos os referenciais de Smith e Hamnett para construção destas análises, assumindo aproximações e admitindo limitações quanto à precisão das análises e resultados. Partindo-se das referências mencionadas notamos um conjunto de parâmetros e condições sobre as quais o processo de gentrificação se verificaria.

Destacamos abaixo alguns desses parâmetros e condições que permitiriam a instalação de um potencial processo de gentrificação e que, em alguma medida, puderam ser observados no distrito da Mooca, totalmente ou parcialmente: a) processo de desinvestimento; b) processo de declínio do centro; c) a atuação do mercado imobiliário na desvalorização 
fundiária; d) ausência de intervenção direta do Estado para evitar o desinvestimento e a "degradação"; e) papel passivo dos proprietários; f) abandono de imóveis por parte dos proprietários; g) o processo de desvalorização atinge certo ponto que permite uma possibilidade de reinvestimento lucrativo por parte de investidores; h) o bairro passa a ser, ao menos parcialmente, assumido por promotores imobiliários; i) inicia-se o processo de investimento, apropriação, renovação, reabilitação; j) as áreas passam por uma valorização e aumento de preços dos aluguéis; k) tem início a chegada de uma nova classe de moradores de renda mais elevada; I) ocorre alguma transformação e elitização do comércio e dos serviços e presença de novos equipamentos culturais mais sofisticados.

Outros fenômenos e condições sugeridas pelos teóricos da gentrificação, listados abaixo, são considerados por nós como parâmetros com baixa aderência para o caso da Mooca: a) o "obsoleto" que pode transformar-se em "estilo"; b) o lugar torna-se alternativo e propício para atração de artistas, com presença de ateliês, públicos alternativos e pioneiros; c) o discurso do poder público explicita a intencionalidade de atrair investidores e elitizar; $d$ ) identifica-se a expulsão "branca" significativa de populares e moradores tradicionais, que deixam o bairro, num processo de substituição de classes sociais.

Diante dos parâmetros delineados acima, nota-se que a hipótese da gentrificação não pode ser plenamente corroborada, principalmente por ausência de análise de dados, no âmbito desta pesquisa, particularmente no que se refere à evolução da renda dos moradores do distrito. Por outro lado, a mesma hipótese não pode ser absolutamente refutada, considerando-se que diversas condições sugeridas no referencial teórico-conceitual apresentado na primeira parte do artigo se verificam em alguma medida, como por exemplo a atuação do Estado, dos proprietários e dos investidores privados, em uma lógica que tende a desembocar em um processo de gentrificação.

Por fim destacar que o processo de desinvestimento público e privado por que passou o centro de São Paulo nas últimas décadas, incluindo-se a Mooca pode ser considerado um ingrediente importante do processo de gentrificação, como apontado por Smith. Na medida em que essa região se torna suficientemente desqualificada e desvalorizada, sobretudo na relação entre o valor da propriedade e o valor da terra, como nos explicou Smith (1996), essa ampla diferença garantirá ao capital imobiliário sobre taxas potenciais de lucros e pode estimular o retorno ao centro de alguns investidores e parte de velhas e novas elites interessadas em investir e residir no centro. 0 padrão dos imóveis lançados no distrito, sobretudo na década de 2000, reforça os indícios de um potencial processo de gentrificação.

Com relação a Mooca, considera-se importante estudar os efeitos da implantação, ainda em sua fase inicial, da Operação Urbana Mooca-Vila Carioca, no processo de expulsão da população de baixa renda, assim como estudar de forma aprofundada em que medida as Zeis demarcadas no distrito podem ou não contribuir para a inclusão socioespacial dos grupos vulneráveis e permitir o fortalecimento de uma política de habitação de interesse social no distrito, evitando os processos de gentrificação.

Conclui-se que, nos últimos anos, ocorreu uma valorização imobiliária associada a uma 
intensificação da atuação do mercado imobiliário na produção e comercialização de novos produtos imobiliários de 3 e 4 dormitórios para classes média e média-alta, associados a uma tendência de elitização nos serviços e comércios para esses novos residentes.

De acordo com a revisão teórica e conceitual realizada na primeira parte do artigo, estes se constituem ingredientes básicos de um processo de gentrificação em região consolidada: valorização imobiliária, lançamentos imobiliários para públicos com renda mais alta, elitização do comércio e dos serviços, discurso oficial do poder público com intenção de transformação/revitalização/requalificação da região.

Considerando a disposição dos atores em cena e as oportunidades de investimentos proporcionadas pela legislação e instrumentos urbanísticos incidentes, como a Operação Urbana Consorciada, vislumbra-se um cenário plausível em que a verdadeira transformação ainda está por vir. Novas pesquisas neste campo são consideradas essenciais.

\section{Michelly Lima Reina}

Universidade Federal do ABC, Programa de Pós-Graduação em Planejamento e Gestão do Território. Santo André/SP, Brasil.

michellyslima@gmail.com

\section{Francisco de Assis Comarú}

Universidade Federal do ABC, Programa de Pós-graduação em Planejamento e Gestão do Território. Santo André/SP, Brasil.

francisco.comaru@gmail.com

\section{Notas}

(1) Entre outros, citamos este como um caso bastante conhecido que se refere ao prédio ocupado por famílias de sem teto, da Av. Prestes Maia. Disponível em: http://jornalggn.com.br/noticia/ prestes-maia-911-um-dos-edificios-abandonados-em-sao-paulo

(2) Particularmente no que se refere a Habi - Superintendência de Habitação Popular da Secretaria de Habitação da Prefeitura de São Paulo.

(3) Disponível em: http://www.procentro.com.br/site/Home.aspx. Acesso em: 12 maio 2012.

(4) A Programa fazia parte da Ação Centro, programa da PMSP, que tinha como objetivo reverter o processo de degradação e abandono do centro da cidade, através da implementação de projetos sociais e intervenções urbanas capazes de qualificarem os espaços públicos e restabelecerem suas potencialidades. 
(5) Projeto Nova Luz. Disponível em: http://www.novaluzsp.com.br/proj_hist.asp?item=projeto. Acesso em: 30 maio 2012.

(6) Processo no 0019326-64.2012.8.26.0053.

(7) Slogan do empreendimento SmartDowntown Living localizado no Brás, foi lançado no final de 2010. Disponível em: http://www.smartliving.com.br/downtown/ Acesso em: 10 nov 2012.

(8) Para este levantamento, os dados oficiais da Prefeitura Municipal, para o município inteiro, contabilizaram as informações somente a partir de 1992, logo, as informações aqui apresentadas serão de 1992 a 1999. Consideramos essa aproximação supondo não alterar significativamente o resultado das análises aqui realizadas.

(9) Um processo que compara um endereço ou uma tabela de endereços para o endereço de atributos de um conjunto de dados de referência para determinar se um determinado endereço cai dentro de um intervalo de endereços associado com um recurso no conjunto de dados de referência. Se um endereço cai dentro da faixa de endereços de um recurso, que é considerado um jogo e uma localização, pode ser devolvido. Disponível em: http://support.esri.com/en/ knowledgebase/GISDictionary/term/address matching. Acesso em: 6 ago 2013.

(10) A título de exemplo, mencionamos dois lançamentos que ocorreram na Mooca na década de 2000. Empreendimento La Dolce Vita Nuova Mooca de 2004. Trata-se de seis torres, cada uma com 27 andares somando 324 unidades de 3 (duas torres) e 4 dormitórios (quatro torres), com áreas uteis que variam de $141,92 \mathrm{~m}^{2}$ a $178,38 \mathrm{~m}^{2}$ e preço à época variando de $\mathrm{R} \$ 2.322,86 / \mathrm{m}^{2}$ a $R \$ 2.584,03 / \mathrm{m}^{2}$. O outro exemplo refere-se ao Central Park Mooca, empreendimento com nove torres com 25 andares cada, sendo duas torres com 3 dormitórios e sete torres com 4 dormitórios, área útil variando de $115,08 \mathrm{~m}^{2}$ até $202,50 \mathrm{~m}^{2}$ com preços entre $\mathrm{R} \$ 2.641,61 / \mathrm{m}^{2}$ a $\mathrm{R} \$ 3.175,27 / \mathrm{m}^{2}$ (Vitale, 2013).

\section{Referências}

BENKO, G. (2002). Economia, espaço e globalização na aurora do século XXI. São Paulo, Hucitec.

BONDUKI, N. G.; ANDRADE, C. R. M. e ROSSETTO, R. (orgs.) (1993). Arquitetura e habitação social em São Paulo 1989/1992. São Paulo, Universidade de São Paulo.

COMARU, F. A. e ABIKO, A. K. (1998). Intervenção habitacional em cortiços na cidade de São Paulo: o Mutirão Celso Garcia. Boletim Técnico da Escola Politécnica da USP. BT/PCC, v. BT/PCC/205, pp. 1-20.

FELIPE, J. P. (1995). Cingapura x Mutirão. Por dentro da polêmica. In: ENTAC 95 - Encontro Nacional de Tecnologia do Ambiente Construído. Anais. Rio de Janeiro, ANTAC, v. II. pp. 447-451.

FERREIRA, J. S. W. (2004). O mito da cidade-global: o papel da ideologia na produção do espaço terciário em São Paulo. Revista Pós-FAUUSP. São Paulo, v. 16.

FIX, M. de A. B. (2009). Uma ponte para a especulação - ou a arte da renda na montagem de uma "cidade global". Caderno CRH. Salvador, v. 22, n. 55, pp. 41-64. 
HAMMET, C. (1991). Transactions of the Institute of British Geographers. New Series, v. 16, n. 2.

IKUTA, F. K. (2008). Práxis e dinâmica territorial da luta pela moradia: articulações, contradições e possibilidades no âmbito do conflito capital x trabalho. Tese de doutorado. Presidente Prudente, Universidade Estadual Paulista.

KARA-JOSÉ, B. (2010). A popularização do Centro de São Paulo: um estudo de transformações ocorridas nos últimos 20 anos. Tese de doutorado. São Paulo, Universidade de São Paulo.

MARQUES, E. (2005). "A dinâmica imobiliária da incorporação em período recente”. In: MARQUES, E. e TORRES, H. (orgs.). São Paulo: segregação, pobreza e desigualdades sociais. São Paulo, Senac.

NAKANO, K.; ROLNIK, R. e CAMPOS, C. M. (2004). "Dinâmicas do subespaço da área central de São Paulo". In: EMURB. Caminhos para o centro estratégias de desenvolvimento para a região central de São Paulo. São Paulo: PMSP, Cebrap, CEM, pp. 124-158

SALES, P. M. e R. BAFFI, M. I. S. (2010). Acerca da permanência e atualização do território industrial e ferroviário do vale do Tamanduateí - São Paulo. Arq.Urb, n. 3.

SANDRONI, P. (2004). "A dinâmica imobiliária da cidade de São Paulo: esvaziamento, desvalorização e recuperação da região central". In: COMIM, Á. (org.). Caminhos para o centro: estratégias de desenvolvimento para a região central de São Paulo. CEM-Cebrap/Emurb. São Paulo, Editora da Unesp.

SILVA, H. M. B. (coord.) (2006). Observatório do uso do solo e gestão fundiária do centro de São Paulo. Relatório da pesquisa. São Paulo, LabHab FAUUSP: Lincoln Institute of Land Policy.

SILVA, H. M. B e SIGOLO, L. M. (2007). Oportunidades e limites para a produção da habitação social no centro de São Paulo. Lincoln Institute of Land Policy.

SMITH, N. (1996). The new urban frontier: gentrification and there vanchist city. Nova York, Routledge.

(2006). “A gentrificação generalizada: de uma anomalia local à "regeneração" urbana como estratégia urbana global". In: BIDOU-ZACHARIASEN, C. (org.). De volta à cidade: dos processos de gentrificação às políticas públicas de "revitalização" dos centros urbanos. São Paulo, Annablume.

(2011). "Gentrification, the frontier, and the restructuring". In: FAINSTEIN, S. S. e CAMPBELL, S. Readings in urban theory. Readings in urban theory. Massachusetts, Blackwell.

TEIXEIRA, A. C.; COMARÚ, F. de A.; CYMBALISTA, R. e SUTTI, W. (2001) Conflitos em torno do direito à moradia na região central de São Paulo. Rio de Janeiro: Ibase: ActionAid: Ford Foundation, 2005.

VILLAÇA, F. (2001). O espaço intra-urbano no Brasil. São Paulo, Studio Nobel/Fapesp.

VITALE, L. (2013). Áreas industriais na orla ferroviária: valorização imobiliária ou valor urbano? Tese de doutorado. São Paulo, Universidade de São Paulo.

Texto recebido em 2/dez/2014

Texto aprovado em 5/mar/2015 